\title{
Rhinoplasty and septumplasty under local anesthesia: our experience in the ORL service of hospital ramos mejía
}

\begin{abstract}
Background: Since the nasal bones and nasal septum are the most fractured bone structures of the human body, the treatment for this condition when the lesion obstructs the nasal airway is surgery, either septumplasty if it is only the Nasal septum the anatomically involved structure, or rhinoseptumplasty when the nasal bones, the nasal valve, the tip, etc. are involved in the obstruction. Septumplasty and rhinoplasty are procedures that correct the anatomical alterations that obstruct the nasal airway and avoid complications. Rhinoseptumplasties and septumplasties can be performed by local anesthesia and intravenous sedation in patients with ASA 1 and 2, without presenting risks and with good esthetic and functional results. The present study analyzes our casuistry of patients operated using local anesthesia and intramuscular sedation.
\end{abstract}

Objective: To assess the degree of satisfaction of patients undergoing rhinosis and septumplasty with local anesthesia and intramuscular sedation, and intra and postoperative results.

Place of Application: Otorhinolaryngology Service of Ramos Mejía Hospital.

Design: Descriptive, prospective study.

Population: Twenty-one patients who underwent rhinosenplasty and septumplasty from April 2014 to October 2014 were included, of which 15 were men $(71.43 \%)$ and 6 women (28.57\%), ranging from 62 And 21 years old.

Methods: Patients with preoperative anesthesia were treated with local anesthesia (lidocaine $+2 \%$ epinephrine) and intramuscular sedation (chlorpromazine, promethazine and meperidine) with indication for rhinosis and septumplasty ASA 1 and ASA 2, Cottle technique was used for septumplasties and closed technique for rhinoseptumplasties with intercartilaginous incision and internal osteotomies.

Results: No surgery had to be interrupted due to intolerance of the patient, nor were there adverse effects of the same. No postoperative complications were observed either. The functional and aesthetic results were acceptable.

Conclusion: The lack of availability of general anesthesia in the municipal hospitals of the Autonomous City of Buenos Aires is not a limitation for this type of intervention in the public domain, since the rhinoseptumplasties and septumplasties with local anesthesia and support with sedation are one Safe alternative for the patient, while reducing the cost in health by not requiring hospitalization for postoperative control.

Keywords: rhinoplasty, septumplasty, local anesthesia
Volume 6 Issue 3 - 2017

\author{
Lopez Moris Carlos B,' Golian Ignacio,' \\ Montes Emiro, ${ }^{3}$ Fiameni Amilcar ${ }^{4}$ \\ 'Jefe de Residentes Servicio ORL Hospital Ramos Mejía, \\ Argentina \\ ${ }^{2}$ Concurrent 5th year ORL Service Ramos Mejía Hospital, \\ Argentina \\ ${ }^{3}$ Resident 2nd year ORL Service Ramos Mejía Hospital, \\ Argentina \\ ${ }^{4}$ Head of ORL Hospital Ramos Mejía, Argentina
}

Correspondence: Golian Ignacio, Concurrent 5th year ORL Service Ramos Mejía Hospital,Argentina,

Email ignaciogolian@yahoo.com.ar

Received: November 14, 2016 | Published: March 27, 2017

\section{Introduction}

Since the nasal bones and nasal septum are the most fractured bone structures of the human body, ${ }_{1}^{1}$ the treatment for this condition when the lesion obstructs the nasal airway is surgery, either septumplasty if only the nasal septum structure Anatomically involved, or rhinoseptumplasty when the nasal bones, the nasal valve, the tip, etc. are involved in the obstruction. ${ }^{2-4}$ Septumplasty and rhinoplasty are procedures that correct the anatomical alterations that obstruct the nasal airway and Avoid complications, ${ }^{5}$ such as obstructive sleep apnea, rhinosinusitis, epistaxis, anosmia, paradoxical hypertrophy of turbinates, among others, ${ }^{6,7}$ being medical management only an adjuvant therapy when the anatomical alterations that obstruct the nasal airway are fully identified. ${ }^{8}$

The etiology of septal deviations may be congenital or acquired, mainly the latter of traumatic origin. ${ }^{9,10}$ Rhinoseptumplastias and sep- tumplasties can be performed by local anesthesia and intravenous sedation in patients with ASA 1 and 2, without presenting risks and with good esthetic and functional results. ${ }^{11}$ There are studies that show that general and local anesthesia in nasal surgical procedures do not have significant difference in how much to the pain, for example, in a reduction of a nasal fracture. ${ }^{12}$ The results in nasosinusal surgeries are good when performed with local anesthesia and sedation, so it can be said that they are a safe practice in our specialty. ${ }^{13}$ In our service, since May 2014, rhinosenphoplasty was resumed with local anesthesia, a practice that in previous years was preferred to perform with general anesthesia. This was decided in order to adapt to the socioeconomic reality that our country lives in these times and to the lack of personnel of anesthesia and medical supplies that carry all the hospitals of the Government of the Autonomous City of Buenos Aires. This practice seeks to reduce the cost in health, the days of hospitalization of patients operated and obtain excellent intra and post-surgical results. 
Currently, we perform 1 to 2 rhinoseptumplasties or septumplasties per week with this technique, on an outpatient basis.

\section{Objectives}

To evaluate the degree of satisfaction of patients undergoing rhinosis and septumplasty under local anesthesia. Evaluate the intra and postoperative results: intraoperative bleeding, intraoperative pain, complications, postoperative pain, postoperative edema and degree of satisfaction.

\section{Place of application}

It was performed in the Otorhinolaryngology Service of Hospital Ramos Mejía in the period from April 2014 to October 2014.

\section{Design}

A descriptive, prospective study was conducted.

\section{Population}

Twenty-one patients were included, of which 15 were male $(71.43 \%)$ and 6 female (28.57\%), aged between 62 and 21years, with a mean age of 32.35 years. Inclusion criteria to undergo surgery were: Patients of any sex or age who would require a rhinoplasty procedure and rhinosis by a septal and / or rhinosis deviation that would condition nasal obstruction and aesthetic deformities. Exclusion criteria were: All rhinoseptumplasties or septumplasties with general anesthesia, whether: non-primary, those that are accompanied by endoscopic and sinus surgery or septal perforation closures at the same time. In addition, the presence of comorbid diseases, such as systemic arterial hypertension, cardiac diseases, diabetes mellitus, collagenopathies, etc. There were 14 rhinoseptumplasties $(66.6 \%)$ and 7 septumplasties $(33.3 \%)$

\section{Methods}

All patients underwent external ENT examination with anamnesis, physical examination, anterior rhinoscopy, and computed tomography of the craniofacial mass without contrast. As preoperative studies, we requested a complete laboratory with coagulation, Chest $\mathrm{x}$-ray, preoperative evaluation, and evaluation by anesthesiologist in anesthesiology outpatient clinic. On the day of surgery, 8hours of fasting were given and promethazine $25 \mathrm{mg}$ ( $1 / 2$ ampoule), chlorpromazine 12.5 $\mathrm{mg}(1 / 2$ ampoule) and meperidine $100 \mathrm{mg}$ ( 1 ampoule) were given 40minutes before Of the intervention, by intramuscular route and $\mathrm{Di}$ clofenac $150 \mathrm{mg}$ and Ranitidine $150 \mathrm{mg}$ by intravenous route to slow drip. Antisepsis was performed with chlorhexidine and sterile fields were placed. It was infiltrated with $2 \%$ xylocaine+epinephrine in nasal septum in submucopericóndrico space for septumplastias, and also in infraorbital region by sub labial route, nasal dorsum, columela and intranasal rumen for rhinoseptumplastias. Cottle technique was used for septumplasties and closed technique for rhinoseptumplasties with intercartilaginous incision and internal osteotomies.

At the end of the intervention, internal nasal splints were placed in septumplasties and external thermomodible nasal splints were also placed in rhinoseptumplasties. Nasal tamponade with perforated gauze was performed and the patient was monitored in the immediate postoperative period in the anesthetic recovery room for approximately 1 hour, then retired on an outpatient basis. It was indicated antibiotic therapy, analgesia, alarm patterns and was quoted at 48 hours for extraction of tamponade and control. At 10days the external and / or internal nasal splints were removed. In the postoperative period, the following variables were evaluated:
Intraoperative bleeding: presence of intraoperative epistaxis, which was classified as: Mild: required normal aspiration and does not hinder vision in the surgical field.

i. Moderate: required greater aspiration than usual and / or intraoperative nasal tamponade with intraoperative time delay, with difficulty in vision of the surgical field.Severe: required electrolyte replacement and / or transfusions, with signs of hypovolemia and suspension of surgery.

ii. Intrasurgical and postsurgical pain: the following verbal scale was used:

iii. Complications: absence or presence of complications, such as anterior and / or posterior epistaxis,facial cellulitis, septal hematoma, septal abscess, septal perforation, saddle nose, synechiae, paraesthesia and / or facial hypoesthesia, supratip, etc.

iv. Post-surgical edema: presence or absence of post-surgical edema.

v. Degree of aesthetic and functional satisfaction: we used a verbal scale comprised of bad, regular, good, very good and excellent.

\section{Results}

Fourteen rhinoseptumplasties $(66.6 \%)$ and seven septumplasties $(33.3 \%)$ were performed in the Otorhinolaryngology Service of the Ramos Mejía Hospital in the period from April 2014 to October 2014 (Figure 1).

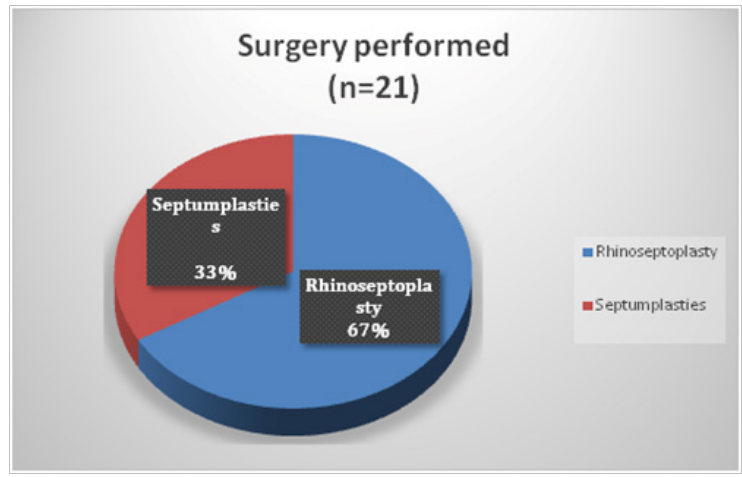

Figure I Surgery performed $(n=2 I)$.

No surgery had to be interrupted due to patient intolerance, nor were there any adverse effects of the surgery. No postoperative complications were observed either. Only one patient had moderate bleeding at surgery $(4.7 \%)$, and all other patients had mild bleeding (95.3\%). None had severe bleeding (Figure 2).

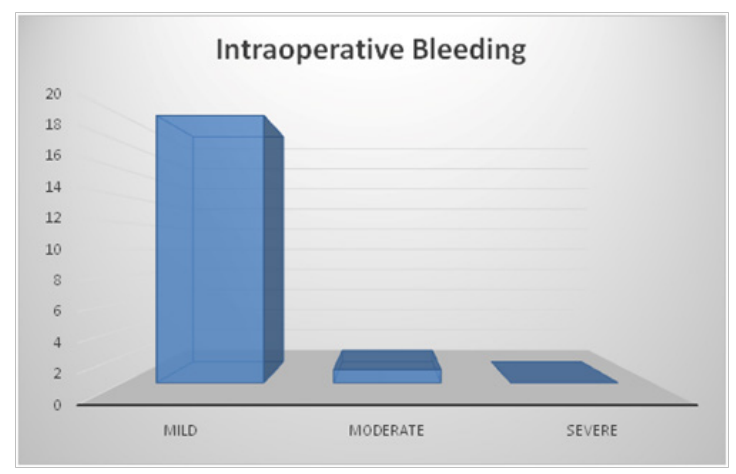

Figure 2 Intraoperative bleeding. 
All septumplasties presented no intra and postoperative pain Rhinoseptumplasties, 9 presented mild intraoperative pain (64\%), of which 2 were women $(22.2 \%)$ and the rest were men (78.8\%); And 5 presented moderate intraoperative pain $(28.5 \%)$, of which 3 were women $(60 \%)$ and 2 men (40\%) (Figure 3$)$.

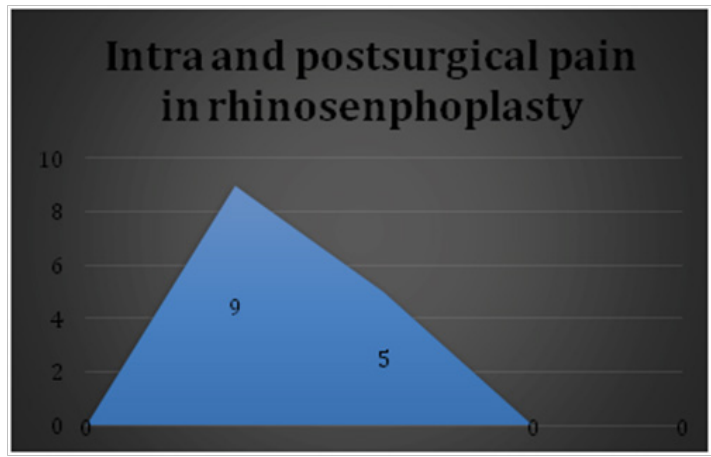

Figure 3 Intra and postsurgical pain in rhinosenphoplasty.

No patient presented postoperative complications, although a patient was not evaluable, since it received a nasal trauma within 7 days of the surgical intervention. Regarding the degree of functional and aesthetic satisfaction, 16 patients reported excellent satisfaction (76.1\%), 2 very good patients $(9.5 \%), 2$ good patients $(9.5 \%)$ and one patient was not Evaluable for suffering nasal trauma in the immediate postoperative period (4.7\%) (Figure 4).

\section{Degree of functional and aesthetic satisfaction}

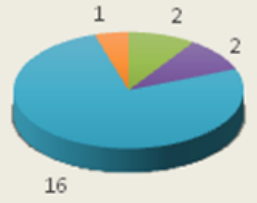

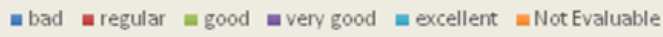

Figure 4 Degree of functional and aesthetic satisfaction.

\section{Conclusion}

None of the surgeries had to be suspended due to intolerable pain or severe bleeding. Septumplasties were better tolerated than rhinoseptumplasties, since the latter presented no intraoperative or post-surgical pain, unlike rhinoseptumplasties, which most presented mild intra- and postoperative pain, but were tolerable for the patient, and relapsed with non-steroidal anti-inflammatory drugs (NSAIDs). Higher tolerance was observed in male patients than in female patients. But no patient referred to the procedure as intolerable. In the literature, local anesthesia with intravenous sedation with midazolam, fentanyl and diphenhydramine has been described, but in the last 10years no published work has been found in which the intramuscular medication described by us has been used, so these results are not comparable. Therefore, the lack of availability of procedures with general anesthesia in the municipal hospitals of the Autonomous City of Buenos Aires is not a limitation to perform this type of interventions in the public domain, since the rhinoseptumplasties with local anesthesia and support with sedation Are a safe alternative for the patient, while reducing the cost in health by not requiring hospitalization for postoperative control. The importance of performing clinical trials comparing this technique with the same procedure under general anesthesia, to consolidate the rhinosenplasty with local anesthesia and sedation as a valid therapeutic alternative, is emphasized.

\section{Acknowledgments}

None.

\section{Conflicts of interest}

Author declares there are no conflicts of interest.

\section{Funding}

None.

\section{References}

1. Bailey BJ, Johnson JT, Newlands SD. Head and Neck Surgery Otolaryngology. (4th edn), Lippincott Williams \& Wilkins USA. 2006. p.289-505.

2. Lalwani AK. Current Diagnosis \& Treatment in Otolaryngology-Head \& Neck surgery. (6th edn), Mc Graw Hill, USA. 2004. p.239-275.

3. Cummings CW, Flint PW. Otolaryngology Head Neck Surgery. (4th edn), Elsevier Mosby, USA. 2005. p.865-1136.

4. Adams W. The treatment of the broken nose by forcible straightening and mechanical apparatus. Br Med J. 1975;2(770):421-422.

5. Arbor P. Nasal airway surgery-concepts and technique. In: Johnson, et al. (Eds.), Instructional courses. 4, St Louis: Mosby, USA. 1999. p.34-56.

6. Asch M. Treatment of nasal stenosis due to deflective septum with and without thickening of the convex side. Laryngoscope. 1899;6(6):340-343.

7. Beck JC, Sie KCY. The growth and development of the nasal airway. Facial Plast Surg Clin North Am. 1999;7:257.

8. Bernstein L. Airway problems after rhinoplasty. Facial Plast Surg Clin North Am. 1995;3:449.

9. Constantinides MS, Adamson PA, Cole P. The long-term effects of open cosmetic septorhinoplasty on nasal air flow. Arch Otolaryngol Head Neck Surg. 1996;122(1):41-45.

10. Cottle MH, Loring RM, Fischer GG, et al. The'maxilla-premaxilla' approach to extensive nasal septum surgery. AMA Arch Otolaryngol. 1958;68(3):301-313.

11. Sklar M, Golant J, Solomon P. Rhinoplasty with intravenous and Local Anesthesia. Clin Plastic Surg. 2013;40(4):627-629.

12. Rajapakse Y, Courtney M, Bialostocki A, et al. Nasal Fractures: a study comparing local and general anaesthesia techniques. ANZ Journal of Surgery. 2003;73(6):396-399.

13. Fedok FG, Ferraro RE, Kingsley CP, et al. Operative times, postanesthesia recovery times, and complications during sinonasal surgery using general anesthesia and local anesthesia with sedation. Otolaryngol Head Neck Surg. 2000;122(4):560-566. 